\title{
The relationships between the combination of person- and organization-related conditions and patients' perceptions of palliative care quality
}

Tuva Sandsdalen ${ }^{1,2^{*}}$ (D) Sevald Høye ${ }^{1}$, Ingrid Rystedt ${ }^{2}$, Vigdis Abrahamsen Grøndahl ${ }^{3}$, Reidun Hov ${ }^{1}$ and Bodil Wilde-Larsson ${ }^{1,2}$

\begin{abstract}
Background: Little is known about the combination of person- and organization- related conditions and the relationships with patients' perspectives of care quality. Such a combination could contribute knowledge reflecting the complexity of clinical practice, and enhance individualized care. The aim was to investigate the relationships between the combination of person- and organization-related conditions and patients' perceptions of palliative care quality.

Methods: A cross-sectional study, including 191 patients in the late palliative phase (73\% response rate) admitted to hospice inpatient care $(n=72)$, hospice day care $(n=51)$, palliative units in nursing homes $(n=30)$ and home care $(n=38)$, was conducted between November 2013 and December 2014, using the instrument Quality from the Patients' Perspective specific to palliative care (QPP-PC). Data were analysed, using analysis of covariance, to explore the amount of the variance in the dependent variables (QPP-PC) that could be explained by combination of the independent variables - Person- and organization-related conditions, - while controlling for differences in covariates.

Results: Patients scored the care received and the subjective importance as moderate to high. The combination of personand organization - related conditions revealed that patients with a high sense of coherence, lower age (person - related conditions) and being in a ward with access to and availability of physicians (organization-related condition) might be associated with significantly higher scores for the quality of care received. Gender (women), daily contact with family and friends, and low health-related quality of life (person-related conditions) might be associated with higher scores for subjective importance of the aspects of care quality.

Conclusion: Healthcare personnel, leaders and policy makers need to pay attention to person- and organization-related conditions in order to provide person-centered palliative care of high quality. Further studies from palliative care contexts are needed to confirm the findings and to investigate additional organizational factors that might influence patients' perceptions of care quality.
\end{abstract}

Keywords: Organization, Palliative care, Patient perception, Person-related conditions, Quality of healthcare, Quality from the patients' perspective specific to palliative care (QPP-PC)

\footnotetext{
* Correspondence: Tuva.Sandsdalen@inn.no

${ }^{1}$ Department of Health Studies, Faculty of Public Health, Inland Norway

University of Applied Sciences, Post box 400, 2418 Elverum, Norway

${ }^{2}$ Department of Health Science, Faculty of Health, Science and Technology,

Discipline of Nursing Science, Karlstad University, 65188 Karlstad, Sweden

Full list of author information is available at the end of the article
} 


\section{Background}

Patients' perspectives and their experience of the care received are considered to be important components for service evaluation; the knowledge gained could inform policy-makers, healthcare managers and healthcare personnel how to help identify potential areas for improvement [1, 2]. National health services are required to have systems that systematically collect patients' experiences of care received $[2,3]$. In the palliative care setting, recruitment of patients and obtaining feedback from patients may be difficult $[4,5]$, because patients have life-threatening illnesses and often have severe physical, psychosocial and existential problems [6], and it may be difficult to locate patients in a palliative phase of illness [7]. Despite these difficulties, it is still important to acquire knowledge about patients' perceptions of palliative care quality.

Healthcare services aims to provide high-quality care to all patients $[2,3]$. What constitutes quality of care in the present study is built on a model developed by Wilde et al. [8]. According to this theoretical framework, the care quality is formed through patient norms, expectations and experience, and an encounter with a care structure [8]. Based on this, care quality can be seen as a measure of patients' perceptions of the actual care received (the perceived reality) and how important the various care aspects are to them (the subjective importance of the care aspects) [9]. Conditions that influence patients' perceptions of care quality can be classified into two areas: person-related conditions and organizationrelated conditions.

\section{Person-related conditions}

Several studies have investigated the relationship between person-related conditions and patients' perceptions of care received. Studies from palliative care settings have found that patients with low levels of education [10], a cancer diagnosis (compared with nonmalignant illnesses) [11-13] and multiple medical conditions $[14,15]$ tend to score the quality of care received as higher. Although some studies have found conflicting results $[15,16]$, this is supported by previous research from other care contexts [17-23].

The perceptions of care quality received seemed to be associated with higher age [17-19, 24-26], higher psychological wellbeing [24] and higher sense of coherence (SOC) [27], and religious affiliation [28]. These studies were conducted in contexts that were not specifically palliative care.

However, previous research seems to be conflicting or uncertain with regard to the association between patients' perceptions of care quality received and; gender $[18,21-24]$, quality of life $[10,16,20]$ and physical health [19, 24, 29].
Time in care may be related to patients' perceptions of care received, as one study found that patients who had been hospitalized for long periods of time rated the care received as higher [22]. However, another study found decreased perception of care received with each additional day in hospital [25].

Patients living alone may experience care differently from patients living with someone [30, 31], but it is not known whether and how this affects their perceptions of care quality. It is well known that family and friends are of important to patients in their late palliative phase of illness [32-34]; however, whether the amount of contact with families and friends is associated with perceptions of care quality is not known.

In relation to patients' perceptions of care received, few studies have investigated the association between patients' perceptions of subjective importance (SI) and person-related conditions in the palliative care context. Rocker et al. [13] found that patients' perceptions of subjective importance differed in according to whether patients were diagnosed with cancer or COPD. Studies from settings that are not specifically palliative care contexts the relationships between person-related conditions and perceptions of SI are therefore either uncertain (few studies) or conflicting (contradictory findings) in terms of age [17, 24, 35], gender [23, 24], patients' SOC $[24,27]$ and patients physical and psychological wellbeing [23, 24].

Studies that have established associations between patients' perceptions of SI and education, multiple medical conditions, living conditions, the amount of contact with family and friends, religious affiliations, quality of life or time in care have not been found.

\section{Organization-related conditions}

Patients' perceptions of care received have previously been shown to be associated with ward characteristics such as types of wards, e.g. specialized versus nonspecialized [36-38]. However, it is not fully known what constitutes these differences in relation to organizational factors. Previous studies have found that the number of nurses or staff $[18,36,39]$ and the qualifications of nurses and physicians $[40,41]$ are related with perceptions of actual care from patient and healthcare personnel perspectives. Further knowledge is needed of the palliative care context.

Nursing care organized as team nursing or primary nursing did not seemed to affect the perception of care received was ascertained in two studies from a general hospital setting [42, 43]. However, in palliative care it has previously been shown that the continuity of care is of the utmost importance to patients receiving such care $[34,44,45]$, so organizational models of both nursing and medical care should enhance continuity. It is 
therefore important to gain knowledge of how the organization of nursing care and physicians' medical care affect patients' perceptions of care received in a palliative care context.

Palliative care includes prevention and relief of physical, psychosocial and spiritual suffering [6], and requires competent healthcare personnel from multiple professions to be available [46], e.g. nurses, physicians, physiotherapists, occupational therapists, nursing assistants, priests, social workers, nutritional physiologists. The availability of multiprofessional staff is important for patients in palliative care $[34,47]$, so it is important to investigate how their availability relates to patients' perceptions of care quality received.

Systematic documentation of patient information in general (e.g. individual care plan, patient care records), and assessment tools for systematic assessment and documentation of symptoms, in particular, are necessary to guide care of high quality $[46,48]$. Documentation and communication of patient information seem to affect care quality $[49,50]$, but studies investigating the association between documentation of patient information and patients' perceptions of actual care in a palliative care context seem to be needed.

Person-centred care (PCC) has been established as an important part of quality of care and involves the acknowledgement of patients' being the centre of care and being respectful of and responsive to individual patient preferences, needs, and values [48]. In the palliative care context, a person-centred model of care has been developed based on the hospice philosophy of care to enhance care quality [51]. Therefore, it is interesting to investigate whether the use of frameworks that emphasize a set of values (such as PCC or hospice philosophy of care) is associated with patients' perceptions of care quality. Two reviews have investigated the effect of PCC in relation to satisfaction and perceived quality of care $[52,53]$. PCC was beneficially associated with perceived quality of care received, but the results were ambiguous. More studies are needed to support or reject these findings [53].

Studies investigating the relationship between organizationrelated conditions and subjective importance have not been found.

\section{Combination of person- and organization-related conditions}

When investigating the combination of person- and organization-related conditions, person-related conditions (e.g., age, gender, time in care and health condition) has been shown to be the strongest predictor whereas organization-related conditions (e.g., choice of hospital, size of hospital, lengths of stay) to a smaller degree were associated with the patients' perceptions of quality of care received $[25,26]$. The impact of personrelated conditions, age, gender and psychological wellbeing on patients' perceptions of care received have been supported in another study from the hospital context, in addition to the organization-related conditions; frequency of over-occupancy and RN headcount [18]. Kirkevold and Engedal [36] found that the care quality in nursing homes from the perspective of the nursing staff were influenced by the person-related conditions; mental capacity, activities of daily living and aggressive behaviour, and the organization-related conditions; type of ward, size of ward and staff to beds ratio influenced the care quality. However, these studies were not performed explicitly in palliative care settings or with patients in the late palliative phase.

Interestingly, studies investigating the relationship between the combination of person- and organizationrelated conditions and patients' perceptions of subjective importance of the care, in either palliative care or other care settings, have not been found.

To sum up, most previous studies that explored the relationship between perceptions of care quality and personal or organization-related conditions had been conducted in settings other than palliative care. Also most studies investigated the relationship between conditions and perceptions of care received, and few explored the relationship between patients' perceptions of subjective importance and person- and organization- related conditions. Little is known about the combination of person- and organization- related conditions and its relationship to patients' perspectives of palliative care quality. Such a combination may contribute to our knowledge, reflecting the complexity of clinical practice and enhancing individualized care.

The aim was to investigate the relationships between the combination of person- and organization-related conditions and patients' perceptions of palliative care quality.

\section{Methods \\ Design}

A cross-sectional study was conducted. The present study is part of a larger study, which has been published $[38,44]$.

\section{Setting}

Participants were recruited from settings representing densely and sparsely populated locations in the eastern part of Norway: two inpatient hospices (HICs), two hospice day-care centres (HDs), two palliative units in nursing homes that specialized in palliative care (PUNHs) and two home-care districts (HCs). The HICs and HD settings, and the PUNHs, may be characterized as specializing in palliative care, because these settings exclusively provide 
palliative care [54]. The home-care settings occasionally providing palliative care may be characterized as nonspecialized palliative care services, although both $\mathrm{HCs}$ did offer specialized trained personnel, such as palliative care teams and cancer nurses, to patients in a late palliative phase. Palliative care is provided by specialist and community care [46]. Hospice services are services with a special dedication to the hospice philosophy and values, and are organized within community care and specialist care [55]. One of the HICs, the two PUNHs and the two HCs were a part of community care. The other hospice inpatient ward and the day hospices were organized within the specialist healthcare services as palliative care units and day-care centres within a hospital.

\section{Participants}

Patients in a late palliative phase were asked to participate in this present study. The late palliative phase was defined as patients being in an advanced phase of their illness, with a 1-year life expectancy [56-58], and received specialized and non-specialized palliative care services [7]. Inclusion criteria were that patients should; be adult ( $\geq 18$ years), understand Norwegian, have no cognitive impairment (which was judged by the registered nurse selected as responsible for recruiting patients $[R R N]$ ), received care from the services for at least 3 days, and have an advanced, life-threatening illness in a late palliative phase (malignant or non-malignant). This was judged and guided by the RRN's negative response to the question: "Would you be surprised if this patient died within the next year?' [56]. To aid an RRN's decision when recruiting patients admitted to nonspecialized services (home care), patients' medical and care records were searched for any indication that the patient was in a palliative phase (e.g. for phrases such as 'advanced cancer/illness' or visits by a palliative care team). This was done because home-care services provided care for a variety of patients, not exclusively patients in a late palliative phase. Additionally, patients included in the study should be aware of being in a palliative phase and receiving palliative care (judged by the RRN). The RRN were encouraged to consult with the patients' physicians and the first author (TS) to discuss any uncertainties that arose about the inclusion criteria and whether or not to include patients in the study.

\section{Instruments}

The instrument Quality from the Patients' Perspective specific to palliative care (QPP-PC) was used to measure patients' perceptions of care from the perspective of patients with various life-threatening illnesses who were receiving help from different services [44]. The QPP-PC is based on the theoretical foundation of the validated general instrument QPP $[8,9,59,60]$ and has previously been psychometrically evaluated and described [44]. The instrument consisted of 52 items divided into 4 dimensions representing quality of care: the medical-technical competence of the caregiver (MT; 10 items), the physical-technical conditions of the care organization (PT; 3 items), the identity-oriented approach of the care givers (ID; 20 items) and the sociocultural atmosphere of the care organization (SC; 16 items). Also included were three single items about medical care, personal hygiene and atmosphere in the ward [44].

Each item (e.g. the best possible help for my pain) were measured in two ways; by patients' experiences of the care received (perceived reality - PR scale) and how important each aspect of care was to the patient (SI scale). PR scale was related to the sentence: 'This is what I experience ..., and SI scale were related to the sentence: 'This is how important this is to me ...'. A 4-point (Likert-type) response scale, ranging from 1 (do not agree at all) to 4 (fully agree), was used for the PR and SI scales: 1 (of little or no importance) to 4 (of the very highest importance). A non-applicable response alternative was available for each item. A mean value was calculated based on the individual participant's response to the items in the respective dimension. In the present study Cronbach's $\alpha$ for the QPP-PC showed $\alpha$ values $>0.7$ for most dimensions $(0.88-0.94)$, except for the PT dimension where $\alpha$ levels were 0.44 for the PR scale and 0.65 for the SI scale.

Person- related conditions comprised 12 conditions: patient characteristics such as age, gender, education, type of diagnosis, number of diagnoses, time in care (the length of patient's experience with care), living conditions, the amount of contact with family and friends, and religious affiliation, SOC, psychological wellbeing and health-related quality of life.

The SOC scale is a validated scale to measure patients' life orientation in terms of how people manage stressful situations and stay well [61]; it comprises questions about comprehensibility, manageability and meaningfulness $[61,62]$. In the present study the Norwegian 13item version with a 7-point scale was used [63]. The SOC index was calculated by adding the score from each item, ranging from 13 to 91 . High scores represent a strong SOC. Cronbach's $\alpha$ was 0.78 in the present study.

Physiological wellbeing was measured by one item from the QPP questionnaire [9], related to the sentence: 'I feel that my physiological wellbeing is ..., using a 5point Likert type scale ranging from 1 ('very poor') to 5 ('very good').

Health-related quality of life was measured using the EQ - VAS (one item) from the EQ-5D-3 L questionnaire of the EuroQol group [64, 65]. EQ-5D-3 L is a validated, standardized, generic measure of health [66] [67] used by patients in various countries and settings, and found 
to be suitable for palliative care [68]. The EQ VAS measures patients' self-rated health on a vertical, visual analogue scale ranging from 0 to 100 , where the endpoints are labelled 'worst imaginable health state' (0) and 'best imaginable health state' (100).

Organization-related conditions included questions related to: setting characteristics (e.g. number of patients a year, number of patients in palliative phase a year, type of diagnosis in the ward), organizational models for nursing and physicians, availability and number of staff (including nurses, cancer nurses, physicians, nursing assistants, physiotherapists, occupational therapists, priests, social workers, nutritional physiologists), personnel's competence in palliative care (formal education for all available personnel), use of theoretical framework (hospice philosophy and PCC), and use of assessment tools (e.g. ESAS) and documentation (e.g. documentation systems used, individual care plan, frequency of documenting that patients were in late palliative phase).

The selection of person- and organization-related conditions was based on a literature review and the researchers' knowledge of the field.

\section{Procedure}

The data collection was conducted between November 2013 and December 2014. Patients were included according to the inclusion criteria, asked to participate, and provided with information about the study and how to fill out the questionnaire by the RRN in each setting. The participants could take all the time that they needed to complete the questionnaire and were instructed to return the questionnaire in a sealed envelope; this was stored in the RRN's office until collection by the researcher. Help with filling out the questionnaire was offered as an interview with one of the researchers (TS). Of the 191 participating patients, 54 were interviewed. Of these, 7 were from HICs, 8 from HDs, 22 from PUNHs and 17 from HCs. The interviews were conducted either in a private room in the ward or in the patients' homes. Each question in the questionnaire were read aloud to the respondents. To make it easier for some patients, the response scales were enlarged on a separate sheet of paper. Patients answered by pointing at the appropriate response category, and/or they answered verbally. The researcher then wrote their responses in the questionnaire following each question.

Data on organization-related conditions were collected from February to March 2015, and focused on data from the year 2014 (time period for the collection of patient data). For the inpatient and day-care settings, data were obtained from the senior charge nurse of the included wards. For the home-care settings, data were obtained from leaders of home-care services in addition to people who were responsible or had expert knowledge of the field or professions, e.g. the district medical officer who had comprehensive knowledge about the community general practitioners (GPs). All respondents received the questions by mail. The author collected the data through personal contact with each ward, by either visiting the ward in person or receiving the data through a combination of phone and email.

\section{Analysis}

IBM SPSS Statistics Data Editor Software [69], version 23, was used to analyse the data. The descriptive statistics, means and standard deviations, were used to describe person- related conditions, organization- related conditions and patients' perceptions of quality of care.

Analysis of covariance (ANCOVA) was performed [69, 70] for each QPP-PC dimension on the PR and SI scales and single items, to explore the amount of the variance in the dependent variables that could be explained by a combination of the independent variables, Person- related conditions and organization-related conditions, while controlling for differences in covariate variables.

The dependent variables represented the four dimensions (MT, PT, ID and SC) and the three single items of the QPP-PC for both the PR and the SI scales. Independent variables represented variables categorized as 'Person-related conditions' and 'organization-related conditions'. Person-related conditions comprised categorically independent variables representing patient characteristics (gender, education, type of diagnosis, number of diagnoses, time in care, living conditions, amount of contact with family and friends, religious affiliation and psychological wellbeing). The continuing variables - age, health-related quality of life (EQ VAS) and SOC - were used as covariates.

The independent variables for organization-related conditions originally comprised items about setting characteristics, organizational models for nursing and physicians, availability and number of multiprofessional staff, personnel's competence in palliative care, use of a theoretical framework, use of assessment tools and documentation. A selection of variables for the final analysis was made based on a research review and the researchers' knowledge of the field, and an evaluation of: if data were complete; if it was possible to compare data/measure at the same level from the four settings (eight wards); and that the number of variables was adjusted according to the number of settings/wards included. The selection process resulted in four included variables: organizational model for physicians, organizational model for nurses, settings with physicians who have achieved palliative medicine as a subspeciality and systematic assessment of symptoms (ESAS).

The data about organization-related conditions were related to each patient staying in the eight care wards/ 
districts (four settings). The ANCOVA analyses were conducted for each dependent variable with the combination of all independent variables (person- and organization-related conditions), for both PR and SI scales (total of 14 analyses).

Cronbach's $\alpha$ was performed, for the QPP-PC, at the dimensional level (single items included) of both scales (PR and SI) and for the SOC instrument. The Cronbach's $\alpha$ values is presented in the description of each instrument and values $>0.7$ were regarded as desirable [69]. Non-response analysis was performed using independent Student's $t$-test and $X^{2}$ test for independence, as appropriate. $P$-value $<0.05$ was considered statistically significant for all analyses.

\section{Results}

Description of person- and organization-related conditions and patients' perceptions of quality of palliative care

A total of 262 patients were asked to participate and 191 returned the questionnaire (response rate $=73 \%$ ). Of the participants, the mean age was 67 years (standard deviation $[\mathrm{SD}]=11.62$, range $41-94$ years), $57 \%$ were female, most had cancer (76\%), had a medium-to-high level of education (75\%), and 51\% were living alone. There were no significant differences between the patients included in the study and those who did not respond $(n=71)$, with regard to age $(P=0.569)$ and gender $(P=0.117)$.

Of the patients that participated, 72 (37\%) were recruited from HICs, 51 (27\%) from HDs, 30 (16\%) from PUNHs and 38 (20\%) from HCs. In the wards recruited, most patients met physicians who worked on the wards $153(80.1 \%)$ and were specialists in palliative care 101 (52.9\%), models of nursing care were mostly organized as primary nursing 128 (67.0\%), and the ESAS was used for most or all patients 150 (78.5\%). Person- and organization-related conditions and patients' perceptions of the care quality are presented in Table 1 .

\section{Patients' perceptions of the care quality}

The mean scores of patients' perceptions of the care received (PR scale) ranged between 3.05 and 3.50 at the dimension level and between 3.51 and 3.89 at the single item level. For patients' perceptions of subjective importance of care aspects (SI scale), the mean scores ranged from 3.17 to 3.50 at the dimension level and from 3.47 to 3.79 for the single items.

The relationships between the combination of person- and organization-related conditions and patients' perceptions of care quality

\section{Significant relationships for the PR scale}

The relationships between the combined person- and organization-related conditions and each of the four dimensions of patients' perceptions of perceived reality are presented in Table 2. The results for patients' perceptions of actual care received (PR scale) showed that the person-related condition 'sense of coherence' was statistically significant related to the dimensions: the MT, PT, ID and SC and the single items about medical care $(P$-value $=0.003)$ and atmosphere $(P$-value $=0.027)$. In addition, age had a statistically significant relationship to the ID dimension and organizational physician's model was statistically significant in the single item about medical care $(P$-value $=0.032)$. This combination of independent variables explained the variance in the dependent variables by: $24 \%$ for MT dimension, $22 \%$ for PT dimension, $30 \%$ for the ID dimension, $28 \%$ for the SC dimension; and for single items: $26 \%$ for medical care $\left(R^{2}=0.257\right)$ and $29 \%$ for atmosphere $\left(R^{2}=0.285\right)$.

\section{Direction of the relationships for the PR scale}

With regard to patients' perceptions of care received (PR scale), their SOC was positively related to the dimensions: the MT, PT, ID and SC (Table 3), and the single items about medical care $(B=0.021, t=3.079)$ and atmosphere $(B=0.008, t=2.270)$. The condition 'age' was negatively related to the ID dimension (Table 3 ). Patients who received care from settings where physicians were available on the wards rated the medical care received higher than those who received medical care from GPs (adjusted mean: 3.934 vs 2.957).

\section{Significant relationships for the SI scale}

The relationships between the combined person- and organization-related conditions and each of the four dimensions of patients' perceptions of subjective importance of care aspects are presented in Table 4 . The results for the SI scale showed that the person-related condition gender had a statistically significant relationship with the MT, PT and ID dimensions - and with the single items personal hygiene $(P$-value $=0.036)$ and atmosphere $(P$ value $=0.013)$. The person-related condition 'amount of contact with family and friends' had a statistically significant relationship with the MT, ID and SC dimensions, and the single item about medical care $(P$-value $=0.29)$. In addition, the 'health-related quality of life' had a statistically significant relationship with the ID dimension. This combination of independent variables explained the variance in the dependent variables by: $18 \%$ for the MT dimension, $18 \%$ for the PT dimension, $30 \%$ for the ID dimension and $24 \%$ for the SC dimension; and for the single items: $19 \%$ for medical care $\left(R^{2}=\right.$ $0.187), 24 \%$ for personal hygiene $\left(R^{2}=0.238\right)$ and $32 \%$ for atmosphere $\left(R^{2}=0.317\right)$.

\section{Direction of the relationships for the SI scale}

For patients' perceptions of importance of care aspects (SI scale), women scored SI higher than men for three out of four dimensions (adj. Mean: for MT 3.20 vs 2.90; 
Table 1 Person- and organization - related conditions and patients' perceptions of care quality $(n=191)$

\begin{tabular}{llc}
\hline Person-related conditions & $n(\%)$ & Missing \\
Age (years) & & 7 \\
$\quad$ Mean score (SD) & $66.80(11.62)$ & \\
Range & $41-94$ & 3 \\
Gender & & \\
Female & $108(57.4)$ & \\
Male & $80(42.6)$ & \\
Education & & \\
$\quad$ Compulsory school or equivalent & $47(25.3)$ & \\
High school or equivalent & $72(38.7)$ & \\
$\quad$ University/university college & $67(36.0)$ & \\
Type of diagnosis &
\end{tabular}

Malignant illness (cancer)/Mixed

159 (83.7)

malignant and non-malignant illnesses

Non-malignant illness (e.g. COPD, HF, MS, ALS, Parkinson's disease)

$31(16.3)$

Number of diagnoses

One diagnosis

Two or more diagnoses

Living conditions

Living alone

Living with a partner/Living with others

Living with children aged $<18$ years

The amount of contact with family or friends

Daily contact

Less than daily contact

Religious affiliation

No

Yes

Sense of coherence (SOC total)

Mean score (SD)

Range

Physiological well-being

Poor/very poor

Neither good or poor

Good/very good

Health-related quality of life (EQ - VAS)

Mean score (SD)

Range

Time in care

$$
\begin{aligned}
& 3-7 \text { days } \\
& 8-30 \text { days } \\
& 31-182 \text { days ( } 1-6 \text { months) } \\
& >183 \text { ( } 6 \text { months) }
\end{aligned}
$$

$110(58.2)$

79 (41.8)

$93(52.2)$

$85(47.8)$

$62.52(11.06)$

29-91

$20(11.8)$

56 (32.9)

$94(55.3)$

$47.92(20.38)$

$0-90$

$32(17.9)$

$52(29.1)$

48 (26.8)

$47(26.3)$
Table 1 Person- and organization - related conditions and patients' perceptions of care quality $(n=191)$ (Continued)

Organization - related conditions related to each patient

Organizational model for physicians

Physician employed/available in the ward

$153(80.1)$

Physician as patient's GP in community care 38 (19.9)

Organizational model for nursing care

Team nursing

$63(33.0)$

Primary nursing

$128(67.0)$

Settings with physicians who have achieved palliative medicine as a subspeciality

Settings with physicians having subspecialty in palliative medicine

Settings without physicians having subspecialty in palliative medicine

Systematically assessment of symptoms (ESAS)

All or most patients

$150(78.5)$

Some or no patients

$41(21.5)$

1

Patients' perceptions of palliative care quality

Perceptions of care received (PR scale) [mean score (SD)]

Medical-technical competence
Physical-technical conditions
Identity-oriented approach

$3.05(0.70) \quad 5$

$3.50(0.59) \quad 5$

$3.35(0.50) \quad 2$

Sociocultural atmosphere

Medical care (single item)

$3.34(0.52) \quad 6$

Personal hygiene (single item)

$3.57(0.73) \quad 5$

$3.51(0.70) \quad 61$

Atmosphere (single item)

$3.89(0.33)$

$68^{*}$

Perceptions of subjective importance (SI scale) [mean score (SD)]

Medical-technical competence

$3.17(0.62) \quad 6$

44

Physical-technical conditions

$3.49(0.55) \quad 6$

Identity- oriented approach

$3.50(0.47) \quad 3$

Sociocultural atmosphere

$3.40(0.49) \quad 5$

21

Medical care (single item)

$3.75(0.53) \quad 5$

Personal hygiene (single item)

$3.47(0.71) \quad 54$

Atmosphere (single item)

$3.79(0.43) \quad 72^{*}$

For categorical variables, $n(\%)$ is presented. For continuous variables, mean (SD) and range are presented

ALS, amyotrophic lateral sclerosis; COPD, chronic obstructive pulmonary disorder; $\mathrm{HF}$, heart failure; MS, multiple sclerosis

*Including 'not applicable' for all home-care patients $(n=38)$

for PT 3.58 vs 3.34; for ID 3.47 vs 3.28) (Table 5), and two single items: hygiene (adj. Mean. 3.90 vs 3.48) and atmosphere (adj. Mean. 3.92 vs 3.61). The SI was also rated higher for patients with daily contact with their families and friends for MT dimension (adj. Mean 3.21 vs 2.90), ID (adj. Mean 3.53 vs 3.22) and SC dimensions (adj. Mean 3.37 vs 3.00) (Table 5), and for the single 
Table 2 The relationships between the combined person- and organization-related conditions and patients' perceptions of perceived reality

\begin{tabular}{|c|c|c|c|c|c|c|c|c|}
\hline & \multicolumn{8}{|c|}{ Perceived reality } \\
\hline & \multicolumn{2}{|c|}{ Medical-technical competence } & \multicolumn{2}{|c|}{$\begin{array}{l}\text { Physical-technical } \\
\text { conditions }\end{array}$} & \multicolumn{2}{|c|}{$\begin{array}{l}\text { Identity-oriented } \\
\text { approach }\end{array}$} & \multicolumn{2}{|l|}{$\begin{array}{l}\text { Sociocultural } \\
\text { atmosphere }\end{array}$} \\
\hline & $F(\mathrm{df}$, error) & $p$ & $F(\mathrm{df}$, error) & $p$ & $F(\mathrm{df}$, error) & $p$ & $F$ (df, error) & $p$ \\
\hline \multicolumn{9}{|l|}{ Person - related conditions } \\
\hline Age & $1.27(1,99)$ & 0.263 & $0.07(1,99)$ & 0.933 & $4.78(1,100)$ & $0.031^{*}$ & $2.74(1,99)$ & 0.101 \\
\hline Gender & $0.03(1,99)$ & 0.857 & $1.57(1,99)$ & 0.213 & $0.03(1,99)$ & 0.956 & $3.28(1,99)$ & 0.073 \\
\hline Education & $0.65(2,99)$ & 0.523 & $0.91(2,99)$ & 0.404 & $0.45(2,99)$ & 0.642 & $0.27(2,99)$ & 0.762 \\
\hline Type of illness & $0.35(1,99)$ & 0.558 & $0.78(1,99)$ & 0.378 & $1.26(1,99)$ & 0.264 & $0.17(1,99)$ & 0.681 \\
\hline Number of illness & $0.85(1,99)$ & 0.359 & $1.61(1,99)$ & 0.207 & $0.04(1,99)$ & 0.843 & $0.02(1,99)$ & 0.883 \\
\hline Time in care & $0.29(3,99)$ & 0.830 & $0.04(3,99)$ & 0.988 & $2.02(3,99)$ & 0.116 & $1.38(3,99)$ & 0.254 \\
\hline Living conditions & $0.90(2,99)$ & 0.409 & $0.51(2,99)$ & 0.605 & $0.95(2,99)$ & 0.390 & $0.78(2,99)$ & 0.462 \\
\hline The amount of contact with family or friends & $0.49(1,99)$ & 0.486 & $0.03(1,99)$ & 0.867 & $3.05(1,99)$ & 0.084 & $2.53(1,99)$ & 0.115 \\
\hline Religious affiliation & $0.60(1,99)$ & 0.440 & $0.14(1,99)$ & 0.710 & $0.07(1,99)$ & 0.788 & $0.11(1,99)$ & 0.738 \\
\hline Sense of coherence & $4.47(1,99)$ & $0.037^{*}$ & $14.92(1,99)$ & $<0.001^{*}$ & $5.56(1,100)$ & $0.020^{*}$ & $10.26(1,100)$ & $0.002^{*}$ \\
\hline Physiological wellbeing & $0.16(2,99)$ & 0.855 & $0.66(2,99)$ & 0.520 & $0.74(2,99)$ & 0.480 & $1.06(12,99)$ & 0.352 \\
\hline Health-related quality of life & $1.55(1,99)$ & 0.216 & $0.44(1,99)$ & 0.507 & $1.59(1,99)$ & 0.210 & $0.21(1,99)$ & 0.647 \\
\hline \multicolumn{9}{|l|}{ Organization - related conditions } \\
\hline Organizational model for physicians & $0.06(1,99)$ & 0.811 & $1.99(1,99)$ & 0.161 & $0.25(1,99)$ & 0.618 & $3.47(1,99)$ & 0.065 \\
\hline Organizational model for nurses & $0.13(1,99)$ & 0.716 & $0.78(1,99)$ & 0.379 & $0.09(1,99)$ & 0.762 & $1.45(1,99)$ & 0.232 \\
\hline Subspecialty in palliative medicine (physicians) & $1.80(1,99)$ & 0.183 & $0.75(1,99)$ & 0.390 & $1.79(1,99)$ & 0.184 & $0.18(1,99)$ & 0.673 \\
\hline Systematic assessment of symptoms (ESAS) & $0.08(1,99)$ & 0.775 & $1.14(1,99)$ & 0.289 & $0.01(1,99)$ & 0.940 & $0.15(1,99)$ & 0.699 \\
\hline$R^{2}$ & 0.243 & & 0.223 & & 0.295 & & 0.278 & \\
\hline
\end{tabular}

${ }^{*}$ Conditions with significance at $p-$ level $<0.05$, measured by ANCOVA analysis

item about medical care (adj. Mean. 3.84 vs 3.60). The 'health-related quality of life' was negatively related to the ID dimension $(B=-0.005, t=-2.198)$ (Table 5).

\section{Discussion}

Patients' scores of the perceived reality could be interpreted as that the quality of care received was moderate to high. These mean scores are lower than the scores obtained using the QPP instrument in a Norwegian study including patients in hospitals (not specifically palliative care) [18], but are in line with scores obtained from patients with lung cancer in a Swedish context [24].
Patients' perceptions of subjective importance of care is lower than in the Swedish study [24]. It is difficult to reach any conclusion based on this, and more studies are needed from the patient perspective in a palliative care context and from the Norwegian context to interpret these results.

The significant association between patients' perceptions of care received (PR scale) and patients' SOC, age and availability of a physician on the ward is not fully supported in previous studies. Studies comprising a combination of person- and organization-related conditions, and their relationships with quality of care received, have been

Table 3 The direction of the significant relationships between the combined person- and organization- related conditions and patients' perceptions of perceived reality

\begin{tabular}{|c|c|c|c|c|c|c|c|c|c|c|c|c|}
\hline & \multicolumn{12}{|c|}{ Perceived reality } \\
\hline & \multicolumn{3}{|c|}{ Medical-technical competence } & \multicolumn{3}{|c|}{ Physical-technical conditions } & \multicolumn{3}{|c|}{ Identity-oriented approach } & \multicolumn{3}{|c|}{ Socio-cultural atmosphere } \\
\hline & $B$ & $t$ & $p$ & $B$ & $t$ & $p$ & $B$ & $t$ & $p$ & $B$ & $t$ & $p$ \\
\hline \multicolumn{13}{|c|}{ Person- related conditions } \\
\hline Age & & & & & & & -0.010 & -2.170 & 0.032 & & & \\
\hline Sense of coherence & 0.015 & 2.102 & 0.038 & 0.025 & 3.993 & $<0.001$ & 0.011 & 2.341 & 0.021 & 0.016 & 3.103 & 0.002 \\
\hline \multicolumn{13}{|c|}{ Organization - related conditions } \\
\hline
\end{tabular}


Table 4 The relationships between the combined person- and organization-related conditions and patients' perceptions of subjective importance

\begin{tabular}{|c|c|c|c|c|c|c|c|c|}
\hline & \multicolumn{8}{|c|}{ Subjective importance } \\
\hline & \multicolumn{2}{|c|}{ Medical-technical competence } & \multicolumn{2}{|c|}{$\begin{array}{l}\text { Physical-technical } \\
\text { conditions }\end{array}$} & \multicolumn{2}{|c|}{$\begin{array}{l}\text { Identity-oriented } \\
\text { approach }\end{array}$} & \multicolumn{2}{|l|}{$\begin{array}{l}\text { Sociocultural } \\
\text { atmosphere }\end{array}$} \\
\hline & $F(\mathrm{df}$, error) & $p$ & $\overline{F(d f, \text { error })}$ & $p$ & $\overline{F(\mathrm{df}, \text { error) }}$ & $p$ & $F$ (df, error) & $p$ \\
\hline \multicolumn{9}{|l|}{ Person - related conditions } \\
\hline Age & $1.00(1,99)$ & 0.321 & $0.18(1,99)$ & 0.671 & $1.39(1,100)$ & 0.241 & $0.26(1,100)$ & 0.611 \\
\hline Gender & $5.63(1,99)$ & 0.020 & $4.60(1,99)$ & $0.035^{*}$ & $5.04(1,100)$ & $0.027^{*}$ & $3.17(1,100)$ & 0.078 \\
\hline Education & $0.71(2,99)$ & 0.401 & $1.35(2,99)$ & 0.264 & $0.12(2,100)$ & 0.897 & $0.15(2,100)$ & 0.864 \\
\hline Type of illness & $0.02(1,99)$ & 0.901 & $0.12(1,99)$ & 0.730 & $0.44(1,100)$ & 0.511 & $0.04(1,100)$ & 0.844 \\
\hline Number of illness & $0.02(1,99)$ & 0.890 & $1.03(1,99)$ & 0.313 & $0.15(1,100)$ & 0.700 & $0.12(1,100)$ & 0.729 \\
\hline Time in care & $0.28(3,99)$ & 0.839 & $1.19(399)$ & 0.319 & $1.94(3,100)$ & 0.128 & $1.04(3,100)$ & 0.378 \\
\hline Living conditions & $0.03(2,99)$ & 0.967 & $0.70(2,99)$ & 0.500 & $0.43(2,100)$ & 0.653 & $0.19(2,100)$ & 0.829 \\
\hline The amount of contact with family or friends & $5.32(1,99)$ & $0.023^{*}$ & $2.79(1,99)$ & 0.098 & $11.65(1,100)$ & $0.001^{*}$ & $12.89(1,100)$ & $0.001^{*}$ \\
\hline Religious affiliation & $0.99(1,99)$ & 0.323 & $0.07(1,99)$ & 0.795 & $0.02(1,100)$ & 0.887 & $0.06(1,100)$ & 0.598 \\
\hline Sense of coherence & $2.09(1,99)$ & 0.151 & $1.80(1,99)$ & 0.182 & $2.02(1,100)$ & 0.158 & $0.83(1,100)$ & 0.336 \\
\hline Physiological wellbeing & $0.61(2,99)$ & 0.544 & $0.35(2,99)$ & 0.707 & $0.14(2,100)$ & 0.869 & $0.51(2,100)$ & 0.603 \\
\hline Health-related quality of life & $0.03(1,99)$ & 0.865 & $0.97(1,99)$ & 0.327 & $4.83(1,100)$ & $0.030^{*}$ & $1.23(1,100)$ & 0.271 \\
\hline \multicolumn{9}{|l|}{ Organization -related conditions } \\
\hline Organizational model for doctors & $1.34(1,99)$ & 0.249 & $0.04(1,99)$ & 0.853 & $0.35(1,100)$ & 0.555 & $0.95(1,100)$ & 0.334 \\
\hline Organizational model for nurses & $0.03(1,99)$ & 0.867 & $0.24(1,99)$ & 0.624 & $0.77(1,100)$ & 0.382 & $2.19(1,100)$ & 0.142 \\
\hline Subspecialty in palliative medicine (physicians) & $0.71(1,99)$ & 0.401 & $0.67(1,99)$ & 0.417 & $0.01(1,100)$ & 0.919 & $1.84(1,100)$ & 0.178 \\
\hline Systematic assessment of symptoms (ESAS) & $1.44(1,99)$ & 0.233 & $0.00(1,99)$ & 0.952 & $0.51(1,100)$ & 0.478 & $0.49(1,100)$ & 0.486 \\
\hline$R^{2}$ & 0.179 & & 0.184 & & 0.296 & & 0.238 & \\
\hline
\end{tabular}

${ }^{*}$ Conditions with significance at $p-$ level $<0.05$, measured by ANCOVA analysis

conducted including patients who are not specifically in their late palliative phase, from wards in hospitals $[18,25$, $26]$ and nursing homes [36]. The significant impact of age was supported by three out of four of these studies [18, $25,26]$, but SOC and availability of physicians were not included in these studies. However, a previous study investigating the association between the person-related condition SOC and quality of care received in wards in the hospital setting [27], found that PR correlated with SOC, especially for the ID and SC dimensions.

Table 5 The direction of the significant relationships between the combined person- and organization- related conditions and patients' perceptions of subjective importance

\begin{tabular}{|c|c|c|c|c|c|c|c|c|c|c|c|c|}
\hline & \multicolumn{12}{|c|}{ Subjective importance } \\
\hline & \multicolumn{3}{|c|}{ Medical-technical competence } & \multicolumn{3}{|c|}{ Physical-technical conditions } & \multicolumn{3}{|c|}{ Identity-oriented approach } & \multicolumn{3}{|c|}{$\begin{array}{l}\text { Socio-cultural } \\
\text { atmosphere }\end{array}$} \\
\hline & B & $t$ & $p$ & B & $t$ & $p$ & B & $t$ & $p$ & B & $t$ & $p$ \\
\hline \multicolumn{13}{|l|}{ Person - related conditions } \\
\hline \multicolumn{13}{|l|}{ Gender } \\
\hline Woman & 0.304 & 2.373 & 0.020 & 0.245 & 2.144 & 0.035 & 0.195 & 2.245 & 0.023 & & & \\
\hline Man & $0^{\mathrm{a}}$ & & & $0^{a}$ & & & $0^{\mathrm{a}}$ & & & & & \\
\hline \multicolumn{13}{|c|}{ The amount of contact with family or friends } \\
\hline Daily contact & 0.316 & 2.307 & 0.023 & & & & 0.317 & 3.413 & 0.001 & 0.369 & 3.590 & 0.001 \\
\hline Less than daily contact & $0^{\mathrm{a}}$ & & & & & & $0^{\mathrm{a}}$ & & & $0^{\mathrm{a}}$ & & \\
\hline Health-related quality of life & & & & & & & -0.005 & -2.198 & 0.030 & & & \\
\hline Organization - related condition & & & & & & & & & & & & \\
\hline
\end{tabular}


The condition 'age' was significantly and negatively related to the ID dimension, which means that older patients rated the care received lower than younger patients. This may indicate that older patients in the present study received care of lower quality. However, this finding contradicts findings from studies performed in settings other than palliative care, which more commonly found that elderly patients rated the quality of care received higher than younger patients [17-21, 24-26]. More studies are needed to clarify how age is related to patients' perceptions of received palliative care.

Patients who received care in settings where physicians were available on the wards rated the care received for the single item about medical care higher than patients receiving medical care from GPs. This may be explained by patients possibly perceiving that access to help from the physicians was more available when on the ward, which led to perceptions of higher quality of medical care received. In the settings included in the present study, care from physicians in hospice inpatient care and day care, as well as palliative units in nursing homes (specialized palliative care), was organized so that physicians were available as part of the staff on a daily basis or for several days a week. For home-care patients, the patients' GPs are responsible for the medical care (nonspecialized palliative care). However, the follow-up and engagement by the GP with patients in the late palliative phases have been found to vary in a recent report evaluating palliative care in Norway [71]. In addition, the reluctance of GPs to make home visits has been pointed out as a challenge for high-quality home care for older patients by the World Health Organization (WHO) [72] Further studies, including organization of medical care from physicians in the palliative care setting, are needed.

Previous studies including both person- and organizationrelated conditions and their relationship to SI have not been identified. However, a few studies have investigated the association of person-related factors with SI and these will further be discussed in relation to the findings of this study.

In this present study, women scored SI significantly higher than men for three out of four dimensions (MT, PT, ID) and two single items: hygiene and atmosphere. This finding is in line with one study from medical and surgical hospital wards conducted in four European countries [23], but different from another study that included patients with lung cancer, which found no relationship between gender and SI [24].

The SI was also rated higher for patients with daily contact with their families and friends, for the MT, ID and SC dimensions and the single item about medical care. A previous study, from an advanced home-care setting, found that family members with daily contact with patients rated the SI higher for aspects of care related to
MT and ID dimensions, than family members who seldom met the patients [73]. The ratings of family who met patients daily were also more in line with patients' scores. This study explained the difference in ratings on SI according to contact with family/patients through an increase in the empathy involved in knowing a person well and sharing constantly changing care experiences [73]. In contrast, two studies found that, for patients, with no close relatives or living alone, who receive palliative care, the identity-oriented aspects of care are of the utmost importance [30,74] compared with the patients living with somebody [30]. It seems that the association between contact with family and patients' perception of importance is not fully understood and needs further investigation.

The 'health-related quality of life' was negatively related to the ID dimension, meaning that patients with a better health-related quality of life scored lower on the importance of the ID dimension. This finding differs from the study of Henoch et al. [24], who found no statistically significant relationships between self-rated physical health and SI of care aspects.

\section{Methodological discussion}

This study has provided the patients' perspectives of palliative care quality with a high number returning the questionnaire (73\%), which is considered to have strengthened the validity of the present study. Those who chose not to respond did not differ with regard to age or gender which reduced the threats of sampling bias [75]. The representativeness [75] was strengthened in the present study by participants with a broad range of time in care and variety of diagnoses being recruited from four different settings, providing both specialized and non-specialized palliative care from both densely and sparsely locations in eastern part of Norway. Even so, not all settings providing palliative care were included, e.g. general units in hospitals and nursing homes. Last, even though patients with a variety of diagnoses were included according to the comprehensive description of the eligible criteria, the results showed that most patients in this study had cancer. The interpretation of the findings must therefore be based on the sample included. A limitation to this study might be that patients' cognitive status was not formally assesses.

The amount of missing data was relatively high for the SOC scale and the EQ - VAS scale. This may be because these two scales were placed in the final section of the questionnaire. This could indicate that those not responding were the patients with poorest health who were too tired to complete the questionnaire. However, the EQ - VAS scores of the responding patients showed that patients with low health status did participate in this study. 
Validated instruments were used to measure quality of palliative care [44]. For the QPP-PC the reliability in this sample was measured using Cronbach's $\alpha$, and the $\alpha$ values were above the desired level of 0.7 for most dimensions apart from the dimension PT $(\mathrm{PR}=0.44$, SI $=0.65$ ). However, this dimension comprised only three items and this may have influenced the low Cronbach's $\alpha$ value observed [69]. The validity of the QPP-PC instrument is strengthened because the instrument measures both the perception of perceived reality and the subjective importance of the care aspects. This becomes visible in this present study by the results for the SI scores showing that the QPP-PC instrument and the present study address important aspects of care.

The amount of missing data for the two single items in the QPP-PC questionnaire about personal hygiene and atmosphere was high. This was mainly because of the 'not applicable' response. For all of the home care patients, the item about the atmosphere was not applicable. For many patients receiving and evaluating day care services, the personal hygiene item was probably not applicable since such help mainly was provided by the home care services before attending day care.

ANCOVA analyses were chosen because most of the independent variables were categorical. Also, by performing ANCOVA, it is possible to control for bias related to differences in the groups and their effects on the results [69], which is considered to be a strength of the present study. In a previously published paper on the same sample, significant differences in patients' age between the settings were shown [38]. In the analysis, age, SOC and health-related quality of life were taken into consideration and controlled for. The variable "organizational model for physicians" varied according to settings of care. This might have influenced the findings. We can therefore not be sure if the results indicate that it is the specialized palliative care settings that influenced patients' perceptions of the medical care (single item), or that it was the physicians availability in these wards.

The model for each dimension on the PR and SI scales explained only about $18-30 \%$ of the variance, leaving approximately $75 \%$ unexplained. It was intended that the present study would include all of the organizationrelated conditions originally collected in the analysis (see Methods). However, the different services included were organized in very different ways and the services registered data about the services in different ways. This made it difficult to use the data collected in a meaningful way. For example, the home-care districts cared for all patients in need of home care, not just patients in the late palliative phase of their illness. In addition, the home-care districts did not register data about the number of patients in the late palliative phase. This made it impossible to calculate the staff per patient ratio in general and for specific professions, which could be an important measure for the amount of care and multiprofessional care available. However, some of the data were registered in the same way and that made these data possible to be included in the analysis of the present study. Future studies are needed to find better ways to measure the number of staff per patient in the homecare setting for this specific patient group, the availability of multiprofessional care and specialist nursing competence, and further to include these in analysis to gather new knowledge of what influences the patients' perceptions of palliative care quality. Also, the way services register organization-related conditions needs to be congruent and comparable.

\section{Conclusion}

The result showed that patients' SOC and age (personrelated conditions), and being in a ward with access to and availability of physicians (organization-related condition), were conditions that might be associated with patients' perceptions of care received. Gender, daily contact with family and friends, and health-related quality of life (person-related conditions) can be associated with the subjective importance that patients perceived their care to be. Although further studies from palliative care contexts are needed to confirm the findings, it is reasonable to suggest that healthcare personnel, leaders and policymakers should pay attention to person- and organization-related conditions in order to provide person-centered palliative care of high quality.

\section{Abbreviations}

ANCOVA: Analysis of covariance; HC: Home care; HDC: Hospice day care: HIC: Hospice inpatient care; ID: Identity-oriented approach dimension; MT: Medical-technical competence dimension; PCC: Person-centred care; PR: Perceived reality; PT: Physical-technical conditions dimension; PUNH: Palliative units in nursing homes; QPP-PC: Quality from the Patients' Perspective specific to palliative care; RRN: Registered nurse responsible for recruiting patients; SC: Sociocultural atmosphere dimension; SI: Subjective importance; SOC: Sense of coherence

\section{Acknowledgements}

The authors wish to thank each of the patients who spent his or her valuable time participating in the present study, the nurses responsible for screening and recruiting the patients, and the leaders and head administrators from the participating wards. In addition, they wish to thank Jari Appelgren for guidance when performing the statistical analysis and writing the manuscript.

\section{Funding}

The present study is part of a doctoral study, financed partly by Inland Norway University of Applied Sciences and partly by the Lovisenberg Diaconal Hospital.

\section{Availability of data and materials}

The data that support the findings of this study is included within the paper. The raw dataset are not publicly available and cannot be shared because that could compromise research participant consent, and since the data will be used for the purpose of further analysis and publications. 


\section{Authors' contributions}

Development of the design and method was conducted by TS, IR, VAG, RH, SH and BWL. TS performed the data collection. Analyses were performed by TS and BWL. The draft manuscript was written by TS. All authors (TS, IR, VAG, $\mathrm{RH}, \mathrm{SH}$ and $\mathrm{BWL}$ ) were involved in reading and revising the manuscript critically, and approved the final manuscript.

\section{Ethics approval and consent to participate}

The study was reported to the Regional Committee for Medical and Health Research Ethics in south-east Norway (REC no. 2013/865), and approved by the Norwegian Social Science Data Services (NSD, no. 34770). Approval for the study to be conducted in the respective settings was obtained by the head administrators of all the wards included. Permission was obtained to use the QPP, SOC scale and EQ-5D-3 L questionnaire.

Verbal and written information about the study and the voluntary nature of participation was provided to each patient. Information was also provided to patients and personnel that, whether or not a patient decided to participate, this would have no consequences for the care of the patient. Verbal and written consent for participating in the study was obtained from the patients. In addition patients were offered an opportunity to withdraw from the study. Patients were encouraged and offered a chance to ask questions about the questionnaire and talk about any emotional aspects that emerged after filling out the questionnaire with the researcher (TS; about the questionnaire and the study) and/or the RRN (about emotional aspects).

\section{Consent for publication}

Consent to publish is not applicable for this present study. The findings are presented for groups of patients, not at an individual level. Patients were informed that their individual responses would not be possible to identify in the results of the study when these were to be published.

\section{Competing interests}

The authors declare that they have no competing interests.

\section{Publisher's Note}

Springer Nature remains neutral with regard to jurisdictional claims in published maps and institutional affiliations.

\section{Author details}

${ }^{1}$ Department of Health Studies, Faculty of Public Health, Inland Norway University of Applied Sciences, Post box 400, 2418 Elverum, Norway.

${ }^{2}$ Department of Health Science, Faculty of Health, Science and Technology, Discipline of Nursing Science, Karlstad University, 65188 Karlstad, Sweden. ${ }^{3}$ Faculty of Health and Welfare Sciences, Østfold University College, Post box 700, 1757 Halden, Norway.

Received: 20 July 2017 Accepted: 14 November 2017 Published online: 06 December 2017

\section{References}

1. World Health Organization (WHO). Quality of care: a process for making strategic choices in health systems. Geneva: WHO; 2006.

2. Ministry of Health and Care Services. God kvalitet - Trygge tjenester Kvalitet og pasientsikkerhet i helse- og omsorgstjenesten. Melding til stortinget nr. 10. [High Quality - Safe Services - Quality and Patient safety in the Health and Care Services. Report to the Storting (Norwegian Parliament) no. 10]. Oslo: Helse- og omsorgsdepartementet; 2012-2013.

3. Darzi A. High quality care for all: NHS next stage review final report. London: Department of Health; 2008

4. Hanson LC, Bull J, Wessell K, Massie L, Bennett RE, Kutner JS, et al. Strategies to support recruitment of patients with life-limiting illness for research: the palliative care research cooperative group. J Pain Symptom Manag. 2014;48:1021-30.

5. Jordhøy M, Kaasa S, Fayers P, Ovreness T, Underland G, Ahlner-Elmqvist M. Challenges in palliative care research; recruitment, attrition and compliance: experience from a randomized controlled trial. Palliat Med. 1999;13:299-310.

6. World Health Organization (WHO). National cancer control programmes: Policies \& managerial guidelines. 2nd ed. Geneva: WHO; 2002.

7. Van Mechelen W, Aertgeerts B, De Ceulaer K, Thoonsen B, Vermandere M, Warmenhoven F, et al. Defining the palliative care patient: a systematic review. Palliat Med. 2013;27:197-208.
8. Wilde B, Starrin B, Larsson G, Larsson M. Quality of care from a patient perspective: a grounded theory study. Scand J Caring Sci. 1993;7:113-20.

9. Wilde B, Larsson G, Larsson M, Starrin B. Quality of care: Developement of a patient-centered questionnaire based on a grounded theory model. Scand J Caring Sci. 1994;8:39-48.

10. Hannon B, Swami N, Krzyzanowska MK, Leighl N, Rodin G, Le LW, et al. Satisfaction with oncology care among patients with advanced cancer and their caregivers. Qual Life Res. 2013;22:2341-9.

11. Murray SA, Boyd K, Kendall M, Worth A, Benton TF, Clausen H. Dying of lung cancer or cardiac failure: prospective qualitative interview study of patients and their carers in the community. BMJ. 2002;325:929-32.

12. Brännström $M$, Hägglund $L$, Fürst $C J$, Boman $K$. Unequal care for dying patients in Sweden: a comparative registry study of deaths from heart disease and cancer. Eur J Cardiovasc Nurs. 2011;11:454-9.

13. Rocker GM, Dodek PM, Heyland DK. Toward optimal end-of-life care for patients with advanced chronic obstructive pulmonary disease: insights from a multicentre study. Can Respir J. 2008;15:249-54.

14. Higashi T, Wenger NS, Adams JL, Fung C, Roland M, McGlynn EA, et al. Relationship between number of medical conditions and quality of care. $\mathrm{N}$ Engl J Med. 2007;356:2496-504.

15. Min LC, Reuben DB, MacLean CH, Shekelle PG, Solomon DH, Higashi T, et al. Predictors of overall quality of care provided to vulnerable older people. J Am Geriatr Soc. 2005;53:1705-11.

16. Miyashita M, Wada M, Morita T, Ishida M, Onishi H, Tsuneto S, et al. Care evaluation scale-patient version: measuring the quality of the structure and process of palliative care from the patient's perspective. J Pain Symptom Manag. 2014:48:110-8.

17. Wilde Larsson B. Patients' views on quality of care: age effects and identification of patient profiles. J Clin Nurs. 1999;8:693-700.

18. Grøndahl VA, Karlsson I, Hall-Lord ML, Appelgren J, Wilde-Larsson B. Quality of care from patients' perspective: impact of the combination of personrelated and external objective care conditions. J Clin Nurs. 2011;20:2540-51.

19. Danielsen K, Garratt AM, Bjertnæs ØA, Pettersen KI. Patient experiences in relation to respondent and health service delivery characteristics: a survey of 26,938 patients attending 62 hospitals throughout Norway. Scand J Public Health. 2007;35:70-7.

20. Sofaer S, Firminger K. Patient perceptions of the quality of health services. Annu Rev Public Health. 2005;26:513-59.

21. Crow R, Gage H, Hampson S, Hart J, Kimber A, Storey L, et al. The measurement of satisfaction with health care: implications for practice from a systematic review of the literature. Health Technol Assess. 2002;6:1-244.

22. Findik UY, Unsar S, Sut N. Patient satisfaction with nursing care and its relationship with patient characteristics. Nurs Health Sci. 2010;12:162-9.

23. Wilde Larsson B, Larsson $G$, Chantereau M, von Holstein K. International comparison of patients' views on quality of care. Int J Health Care Qual Assur. 2005:62-73.

24. Henoch I, Lövgren M, Wilde-Larsson B, Tishelman C. Perception of quality of care: comparison of the views of patients' with lung cancer and their family members. J Clin Nurs. 2011;21:585-94.

25. Péfoyo AJK, Wodchis WP. Organizational performance impacting patient satisfaction in Ontario hospitals: a multilevel analysis. BMC Res Notes. 2013;6:509.

26. Thi PLN, Briancon S, Empereur F, Guillemin F. Factors determining inpatient satisfaction with care. Soc Sci Med. 2002;54:493-504.

27. Wilde Larsson B, Larsson G. Patients' views on quality of care: do they merely reflect their sense of coherence? J Adv Nurs. 1999;30:33-9.

28. Benjamins MR. Does religion influence patient satisfaction? Am J Health Behav. 2006;30:85-91.

29. Törnkvist L, Gardulf A, Strender L. Patients' satisfaction with the care given by district nurses at home and at primary health care centres. Scand J Caring Sci. 2000;14:67-74.

30. Hanratty B, Addington-Hall J, Arthur A, Cooper L, Grande G, Payne S, et al. What is different about living alone with cancer in older age? A qualitative study of experiences and preferences for care. BMC Fam Pract. 2013;14:22-9.

31. Ek K, Sahlberg-Blom E, Andershed B, Ternestedt B-M. Struggling to retain living space: Patients' stories about living with advanced chronic obstructive pulmonary disease. J Adv Nurs. 2011;67:1480-90.

32. Strohbuecker B, Eisenmann Y, Galushko M, Montag T, Voltz R. Palliative care needs of chronically ill nursing home residents in Germany: focusing on living, not dying. Int J Palliat Nurs. 2011;17:27-34.

33. Singer PA, Martin DK, Kelner M. Quality end-of-life care: Patients' perspectives. J Am Med Assoc. 1999;281:163-8. 
34. Sandsdalen T, Hov R, Høye S, Rystedt I, Wilde-Larsson B. Patients' preferences in palliative care: a systematic mixed studies review. Palliat Med. 2015;29:399-419.

35. Wilde-Larsson B, Larsson G, Kvist LJ, Sandin-Bojö A-K. Womens' opinions on intrapartal care: development of a theory-based questionnaire. J Clin Nurs. 2010;19:1748-60.

36. Kirkevold $\varnothing$, Engedal $K$. The quality of care in Norwegian nursing homes. Scand J Caring Sci. 2006;20:177-83.

37. Addington-Hall JM, O'Callaghan AC. A comparison of the quality of care provided to cancer patients in the UK in the last three months of life in in-patient hospices compared with hospitals, from the perspective of bereaved relatives: results from a survey using the VOICES questionnaire. Palliat Med. 2009:23:190-7.

38. Sandsdalen T, Grøndahl VA, Hov R, Høye S, Rystedt I, Wilde-Larsson B. Patients' perceptions of palliative care quality in hospice inpatient care, hospice day care, palliative units in nursing homes, and home care: a crosssectional study. BMC Palliat Care. 2016:15:79.

39. Aiken LH, Clarke SP, Sloane DM. Hospital staffing, organization, and quality of care: cross-national findings. Nurs Outlook. 2002;50:187-94.

40. Engelberg RA, Downey L, Wenrich MD, Carline JD, Silvestri GA, Dotolo D, et al. Measuring the quality of end-of-life care. J Pain Symptom Manag. 2010;39:951-71.

41. Aiken LH, Sloane DM, Bruyneel L, Van den Heede K, Griffiths P, Busse R, et al. Nurse staffing and education and hospital mortality in nine European countries: a retrospective observational study. Lancet. 2014;383:1824-30.

42. Sjetne IS, Veenstra M, Ellefsen B, Stavem K. Service quality in hospital wards with different nursing organization: Nurses' ratings. J Adv Nurs. 2009;65:325-36.

43. ML W, Courtney M, Berger G. Models of nursing care: a comparative study of patient satisfaction on two orthopaedic wards in Brisbane. J Adv Nurs. 2000:17:29-34

44. Sandsdalen T, Rystedt I, Grøndahl VA, Hov R, Høye S, Wilde-Larsson B. Patients' perceptions of palliative care: adaptation of the quality from the Patient's perspective instrument for use in palliative care, and description of patients' perceptions of care received. BMC Palliat Care. 2015;14:54.

45. Waibel S, Henao D, Aller M-B, Vargas I, Vázquez M-L. What do we know about patients' perceptions of continuity of care? A meta-synthesis of qualitative studies. Int J Qual Health Care. 2011;24:39-48.

46. Norwegian Directorate of Health. Nasjonalt handlingsprogram for pallliasjon i kreftomsorgen. Nasjonale faglige retningslinjer. Rapport nr. IS-2285. [National action program for palliative cancer care. Report no. IS-2285]. Oslo: Sosial- og helsedirektoratet; 2015.

47. Virdun C, Luckett T, Davidson PM, Phillips J. Dying in the hospital setting: systematic review of quantitative studies identifying the elements of endof-life care that patients and their families rank as being most important. Palliat Med. 2015:29:774-96.

48. Institute of Medicine. Crossing the quality chasm: a new health system for the $21^{\text {st }}$ century. Washington DC: National Academy Press; 2001.

49. Chaudhry B, Wang J, Wu S, Maglione M, Mojica W, Roth E, et al. Systematic review: impact of health information technology on quality, efficiency, and costs of medical care. Ann Intern Med. 2006;144:742-52.

50. Kripalani S, LeFevre F, Phillips CO, Williams MV, Basaviah P, Baker DW. Deficits in communication and information transfer between hospital-based and primary care physicians: implications for patient safety and continuity of care. JAMA. 2007;297:831-41.

51. Ternestedt B-M, Andershed B, Eriksson M, Johansson IA. Good death: development of a nursing model of care. J Hosp Palliat Nurs. 2002;4:153-60.

52. McMillan SS, Kendall E, Sav A, King MA, Whitty JA, Kelly F, et al. Patientcentered approaches to health care: a systematic review of randomized controlled trials. Med Care Res Rev. 2013;70:567-96.

53. Dwamena F, Holmes-Rovner M, Gaulden CM, Jorgenson S, Sadigh G, Sikorskii $A$, et al. Interventions for providers to promote a patient-centred approach in clinical consultations. Cochrane Database Syst Rev. 2012;12:CD003267.

54. European Association for Palliative Care (EAPC). White paper on standards and norms for hospice and palliative care in Europe: part 1. Recommendations from the European Association for Palliative Care. Eur J Palliat Care. 2009; 16:278-89.

55. Norwegian Directorate of Health. Rapport om tilbudet til personer med behov for lindrende behandling og omsorg mot livets slutt - å skape liv til dagene. Rapport nr. IS-2278. [Report on services for persons in need of palliative care towards the end of life - to create life to the days. Report no. IS-2278]. Oslo: Sosial- og helsedirektoratet; 2015.
56. Thomas K. et al. Prognostic Indicator Guidance (PIG). The Gold Standards Framework Centre In End of Life Care. 4th ed. October 2011. http://www. goldstandardsframework.org.uk/cd-content/uploads/files/General\%20Files/ Prognostic\%20Indicator\%20Guidance\%200ctober\%202011.pdf. Accessed 19 July 2017.

57. Jarlbæk L, Tellervo J, Timm H. Målgrupper og tidspunkter for palliativ indsats. Omsorg. 2014:24-9.

58. Grov EK. The cancer trajectory: a model of phases. Nordic J Nurs Res. 2014; 34:46-7.

59. Larsson G, Wilde Larsson B, Munck IME. Refinement of the questionnaire 'Quality of care from the Patient's Perspective' using structural equation modelling. Scand J Caring Sci. 1998;12:111-8.

60. Wilde Larsson B, Larsson G. Development of a short form of the quality from the Patient's perspective (QPP) questionnaire. J Clin Nurs. 2002;11:681-7.

61. Eriksson M, Lindström B. Validity of Antonovsky's sense of coherence scale: a systematic review. J Epidemiol Community Health. 2005;59:460-6.

62. Antonovsky A. The structure and properties of the sense of coherence scale. Soc Sci Med. 1993;36:725-33.

63. Eide C. Livsorientering, livsstil og helsevaner, en spørreundersøkelse av niendeklasse-elever [Life orientation, lifestyle and health habits: an investigation of pupils in year nine]. Bergen: University of Bergen; 1991.

64. EuroQol Group. EuroQol-A new facility for the measurement of healthrelated quality of life. Health Policy. 1990;16:199-208.

65. Brooks R. EuroQol: the current state of play. Health Policy. 1996:37:53-72.

66. Rabin R, de Charro F. EQ-5D: a measure of health status from the EuroQol group. Ann Med. 2001;33:337-43.

67. Hurst NP, Kind P, Ruta D, Hunter M, Stubbings A. Measuring health-related quality of life in rheumatoid arthritis: validity, responsiveness and reliability of EuroQol (EQ-5D). Rheumatology (Oxford) 1997; 36:551-559.

68. Färkkilä N, Torvinen S, Roine RP, Sintonen H, Hänninen J, Taari K, et al. Health-related quality of life among breast, prostate, and colorectal cancer patients with end-stage disease. Qual Life Res. 2014;23:1387-94.

69. Field A. Discovering statistics using SPSS. 4th ed. Los Angeles: Sage; 2013

70. Tabachnick BG, Fidell LS. Analysis of covariance. In: Tabachnick BG, Fidell LS, editors. Using multivariate statistics. 6th new international ed. Essex: Pearson; 2014. p. 235-84.

71. Melby L, Das A, Halvorsen T, Steihaug S. Evaluering av tjenestetilbudet til personer med behov for lindrende behandling og omsorg. Rapport nr. A27799. [Evaluation of the provision of services to people in need of palliative care. Report no. A27799]. Version 1.1. SINTEF (Stiftelsen for industriell og teknisk forskning ved NTH); 2017.

72. World Health Organization (WHO). Palliative care for older people: Better practice. Copenhagen: WHO; 2011.

73. Wilde Larsson B, Larsson G, Carlson SR. Advanced home care: patients' opinions on quality compared with those of family members. J Clin Nurs. 2004;13:226-33.

74. Dzul-Church V, Cimino JW, Adler SR, Wong P, Anderson WG. "I'm sitting here by myself...": experiences of patients with serious illness at an urban public hospital. J Palliat Med 2010; 13:695-701.

75. Polit DF, Beck $C T$. Nursing research: generating and assessing evidence for nursing practice. 4th ed. Philadelphia: Wolters Kluwer Health; 2014.

\section{Submit your next manuscript to BioMed Central and we will help you at every step:}

- We accept pre-submission inquiries

- Our selector tool helps you to find the most relevant journal

- We provide round the clock customer support

- Convenient online submission

- Thorough peer review

- Inclusion in PubMed and all major indexing services

- Maximum visibility for your research

Submit your manuscript at www.biomedcentral.com/submit 